\title{
Bioterrorism; Dual Use of Technology and Role of Law Enforcement to Combat Biological Attack
}

\author{
Tahir ul Gani Mir*, Prama Rani and Adeebullah Nawim \\ Lovely professional University, Jalandhar, 144411, Punjab, India \\ *Corresponding author
}

\begin{abstract}
A B S T R A C T
\section{Keywords}

Biotechnology,

Bioterrorism,

Microbial forensics

Article Info

Accepted:

12 August 2020

Available Online:

10 September 2020

The threat of Bioterrorism is frequently emerging as a result of rapid growth in technological skills. molecular biological sciences and biotechnology. The critical factor contributing to the scale of this problem is the increasing proliferation of transnational terrorists and their access to funding, equipment and skills for developing biological weapons. A bioterrorism threat must be identified and controlled to reduce adverse health consequences and prevent fatality. This article addresses the issue of risk of bio crimes and needs to forensic science to prevent the discharge of potentially hazardous microbes and what techniques can be employed by the investigators for their fellow citizens to ensure not to engage in dual use of medical research and act ethically because biological weapons can be used intentionally during the war and terrorism. Theoretically, the biological agent could be release with bad intention to dominate the public and gain power.
\end{abstract}

\section{Introduction}

Microbiology is a science of microorganisms which includes various sub disciplines including virology, bacteriology, mycology, parasitology etc. There has been a close link between humanity and microbial diversity since the prehistoric age. Presently, the microbiology field has made great progress that with changing times, microbes are practiced for various purposes such as the production of different products like dairy products, antibiotics, vaccines, and mass destruction also (Cohen et al., 2002). However, it also true that with changing time, the pathogenicity of the microbes becomes virulent and resistant. Due to the emergence of a new pathogen such as viruses and bacteria and recent advancements in this field made these microbes more devastating and posing serious problems. The military as well as terrorist organizations from several countries are using these microbes as a bioweapon to control and create havoc in population. Microbes have been used as bioweapons for a long time when just limited information was known (Panghal and Flora, 2019). Bioterrorism and bioweapon have potential of causing mass death vigorously. Due to widespread nature, difficult to control of disease effect many countries have agreed to ban bio weapons. In 2013 a total of 180 
states signed the Biological Weapon Convention (BWC) and under the terms of BWC use of a bio-weapon in war is prohibited and development of biological weapons such as testing, producing, and stockpiling is also prohibited (Majumdar, 2017). However, in several states and countries research on bioweapon continued to pursue biological warfare. They are developing deadly bioweapons which are cheaper than a nuclear weapon (Means, 2019). Microbial forensics is characterized as a new and evolving method of forensic analysis for Identification and detection of reliably measured molecular variations between microbial strains their origin and relationship or route of transmission of a given isolate (Mohit Bhatia, Bibhabati Mishra, Archana Thakur, Vinita Dogra, 2016). Over the last years, microbial forensics has emerged as a new scientific discipline to improve the strength of law enforcement response against action against such events of bioterrorism (Budowle et al., 2007).

\section{Microbiology as bio war agent}

Microbes are omnipresent in existence and exist anywhere, such as in soil, food, water, humans, etc. They play a significant role throughout all areas of human life The positive role of microorganisms in human welfare such as help in the normal physiological process as digestion, adsorption, etc. has been well known since antiquity. However, much of the work in recent years has concentrated on the pathogenic existence of microbes, and therefore their virulent behavior overweighs their symbiotic role in the present age (Sathua and Flora, 2019). These bio-agents or bioweapons include viruses, bacteria, fungi, and many other toxic chemicals. Such agents are found in nature but these agents can also be intentionally mutated to increase their death or disease capability. There are several microorganisms uses as a bioweapon but as we compare virus depend on blood transfer so they can't be easily spread, so microbes that can transfer through air, water and food are mainly used as a bioweapon. Bioweapon production needs high-technology with current state and attack without financial and technical support is impossible (Naeem et al., 2019)

\section{Brief history}

In ancient time also people were aware of some diseases which can spread by the diseased person. This results in a defensive measure such as separation of people and quarantine and throwing the diseased body into the area administered by the enemy. For example, in $18^{\text {th }}$ and $19^{\text {th }}$ century there was a rumor that white Americans deliberately infected Indians with smallpox (Graubard, 1947). During first world war, Germany was suspected of infecting animals of rival countries with Glanders (Burkhloderia mallei) and Anthrax (Bacillus anthracis). Throughout the Sino-Japanese War (1937-1945) and after the 2nd World War, Unit 731 of Japanese army carried out human experimentation on thousands, primarily Chinese, Koreans, Russians, and Americans, as well as other Japanese mainland criminals. Unit 731 used plague tainted fleas and cholera flies to kill China's population and military (Saalbach, 2019) There are many evidences in the literature where many countries used bio agents to dominate their opponents. The COVID-19 crisis has included biological warfare allegations. The existence of an innovative biological lab in Wuhan has given rise to some hypotheses and allegations of a deliberate attack by China. Considering the trait of an perfect biological war and contrasting the characteristics of a coronavirus, the allegations seems baseless (Tara Kartha, 2020). 
Some other renowned examples of biowarfare include: tricothecen a form of mycotoxin, potentially used in the famous 1981 yellow rain incident that still exists as a point of discussion without proven conclusive evidence (Tucker, 2001). A gastroenterologist in the United States (U.S) was accused of murder by Injecting blood derived from HIV patient into the body of his ex-girlfriend. One prominent well-publicized bio-crime involves the misuse of 'ricin' in Europe to kill a Bulgarian refugee. A laboratory staff who purposely infects one of his colleagues with Shigella dysenteriae in Texas. Use of Salmonella typhimurium in Oregon by infecting local food courts to prevent people from voting. this act of biocrime was politically motivated (Carus, 1998). Many countries have established bio-warfare programs to develop bioweapons that can be used to target crops and animal farms of their rival countries to cause denying food supply and causing economic damage. During World War I, German saboteurs used Anthrax and Glanders to infect over 3,500 horses before being sent from U.S. ports to British and French armies. During second world war, the US and Canada secretly created anti-livestock agents such as rinderpest, an exceptionally lethal cattle disease, during World War II. During the 1960s and early 1990s, Soviet Union 's anti-agricultural warfare program employed some 10,000 employees and attacked chickens, livestock and crops. In 1952, Kenyan nationalists from Mau Mau campaign used a native poisonous plant called African milk bush to kill cattle at a British mission station. In the early 1980s in Sri Lanka, as part of a government undermining program, a community of Tamil separatists attempted to disseminate plant diseases among rubber and tea plantations. Cuba accused the U.S. of conducting 12 chemical assaults on people, animals and crops between 1964 and 1967. Such allegations were groundless, proven by inquiry. In the 1980's,
Saddam Hussein developed a variety of fungal agents in Iraq to target the staple food crops in Iran.

In order to identify and tracing bio agents, the United States Centers for Disease Control and Prevention (CDC) has categorized three possible categories of biological agents, based on ease to disseminate, rate of mortality, social disruption, and public health readiness and public health planning requirements (Table 1).

\section{Microbial forensics}

The emerging field of microbial forensics combines microbiology and forensics. In contrast to public health research, microbial forensics involves an association of the population with the source of the causative agent. Microbial forensics measures molecular variations, origin, relationship, or transmission path between the associated microbial strains. Different modern genetic techniques (molecular phylogeny, DNA fingerprinting, genome- sequencing, etc.) provide accurate interpretations of microbial forensic research and study (Pattnaik and Jana, 2005). Microbial forensics is a multidisciplinary area that relies heavily on the fundamentals of conventional forensic sciences, epidemiology, microbiology, and molecular biology. Forensics labs provide well established protocols for the technical review of facts on all facets of solving crime scenes. For cases involving microbial forensics specific methods are being created. The aim is to build a system to obtain, process, examine, and evaluate microbial forensic evidence in a technically reliable manner and, thus, legally defensible. From the point of view of microbial forensics, the determination of specific strains of bio agents is important. System and method development for identification and the tracking of bioattacks would increase national 
security. The Federal Bureau of Investigation (FBI) has established the formation of the Scientific Working Group on Microbial Genetics and Forensics (SWGMGF) to form a strong base for in the field of microbial forensics. Several more nations are yet to adopt such systems to build the capacity to monitor and plan for unexpected incidents of biological terrorism and biocrimes (Pattnaik and Jana, 2005). Several questions must be addressed during an investigation into the accident in the case of a bioterrorism threat. The health of both the public and the first responders, the location of alleged site, collection and transport of the samples, detection of the agent and tracing source of the detected agent should be hampered by these questions and problems (Echeonwu et al., 2018).

\section{Collection, packing, and transport of evidence}

The effective and most commonly recognized strategy for sampling a bio crime scene is to adopt established guidelines in combination with expertise, scientific knowledge, and good judgment. Often it is important to invent or to use logical methods even without a specified sampling technique or approach because it is better to collect evidence rather than neglect it altogether.

The operational strategy for sampling the evidence should address the uncertainty surrounding it. All procedures and details must be well-documented for potential reference and review. Sampling areas, locations, agent types, substrates, and combinations are almost always new in most microbial forensic cases. This may particularly relate to trace evidence. In fact, there must be some variability in the sampling processes, as every crime scene is distinct as well as the variance of microbial evidence can be immense (Budowle et al., 2006).
Evidence from bio crime science are collected using three basic approaches. One approach is to collect and transfer the whole item into an appropriate biocontainment facility for further sampling and analysis. The place should have been previously proved to be free of contamination. This method decreases the time for collecting evidence. it is mandatory for investigators to wear PPE kit during sample collection. Once the item has been transferred to a safe place, the appropriate sample collection can be done under suitable biocontainment conditions. Certain items are too large to move from the crime scene or there may be a chance that evidence may be lost or damaged during transport. in such a case, the investigator may collect a part of the evidence by vacuuming, filtration, dissolving, etc. Evidence collection techniques and tools must be validated concerning possible analysis procedures. Media for the collection and transportation of pathogens have been developed to preserve nucleic acids, proteins, and the viability of pathogens. Many animal viruses are greatly affected by $\mathrm{pH}$ and ion strength. Tryptose broth is one of the most commonly used transport media. Buffered glycerin has been shown to preserve the bioagent at room temperature over significant periods. Glycerol can inactivate some viruses at specific concentrations whereas some other viruses are retained in clinical samples. The use of isotonic solutions with neutral $\mathrm{pH}$ could be a potential attribute to choose an appropriate collection and transport medium for agricultural viruses (Budowle et al., 2006). Nature and circumstances in which evidence is transported and preserved will indeed affect the outcome of experimental analysis. For certain microbes, storage and transport conditions vary. Anaerobic microbe dies when subjected to ambient oxygen level during storage and cannot, therefore be retrieved through anaerobic culture (Hentges, 1996). Based on state of the sample (e.g. liquid or powder), the circumstances for 
packaging or preservation needed for a specific microorganism can also be different.

A suspected bio-crime event involving an unexpected incidence or where the spread of the infection is unique. The samples to be collected comprise all content therein scenes marked with time and location of the collection. Each sample should be deemed harmful and analyzed the only laboratory with strict standards of bio-safety. Microbial evidence may be collected from a viable microbial agent, nucleic acid, victims' clinical specimen, laboratory instruments, environmental materials, contaminated clothes, etc. Sampling without delay in time is of immense value as evidence may be rapidly destroyed and lost. The forensic technique for sample collection should be flexible, accurate, and effective, in order to identify suspected pathogens or contaminants (Mohit Bhatia, Bibhabati Mishra, Archana Thakur, Vinita Dogra, 2016)

\section{Investigation Strategies}

The release point of bio agent from a known location can easily be traced to a particular small area that is visibly contaminated. Conversely, the specific site of release may be unknown, but information can be collected that contributes to point that location, such as casualties, high infection rate, and distressed locations. A biological attack crime scene investigator aims to collect adequate biological material and relevant agents to enable successful forensic analysis for the detection of organisms and strain or toxin. Nevertheless, the biological element alone is not the only forensically important material that must be regarded, conventional forensic evidence like fingerprints, and other evidences may provide insights about the individuality of a person who committed the offense. In order to obtain the precision of the data to justify the attribution, it is necessary to consider appropriate size, method, number, and location for sample collection. Besides, it is mandatory to maintain the validity and integrity of the evidence from collection through processing and subsequent storage, to a maximum possible; otherwise critical and reliable evidence may be destroyed or lost. In situations of biocrimes conventional specific crime scene response techniques can be employed. medical assistance for victims and the possible health safety risks are the first concern. Securing the crime scene is the next step. The accident reported can include many scenes so it may be challenging to assess the scenario. Organized meetings should be then conducted by law enforcement, public safety authorities, and Environmental Protection Authority to examine the positions and ability to tackle the biological assault both overtly or covertly. Such considerations will provide better standards for collecting and evaluating evidence, selection of control samples to measure the toxicity, contamination and exposure thresholds, effective use of safety as the use of PPE, and recovery efforts in public health (or agriculture). decontamination activities should not be enforced before the collection of forensic evidence for investigative purposes to be carried out. Investigating bio attack usually consist of three inter-related stages-

Identification- It is the stage wherein the bio agent used to characterize the threat is identified. If attacks are concealed, they cannot be identified before the symptoms of the disease emerge from a population. The pathogens would then primarily be known from the response of animals or public health and safety rather than the response of microbial forensics. However, in the case when the attack is overt i.e. when the attacker revels about the attack then as in an open situation the proper response would be from a microbial forensic point of view. A microbial forensic strategy would also be sufficient 
where investigators depend on intelligence knowledge to identify the attack before it is carried out.

Characterization- The second step in bio crime investigation concerns the process of determining whether the incident was deliberate or accidental. Unless the perpetrator reveals his plans to unleash a pathogen, this process will be inevitable. But, when an epidemic has uncommon characteristics and therefore assumes the intentional release of a pathogen, or when the attacker only takes liability after the symptoms of the disease begin to show, the identification of the origin of the disease is crucial.

Attribution- This third step called source tracing, pursue to recognize the source of the pathogens and the perpetrator. This will also generate valuable evidence to combat bioterrorism attack (Echeonwu et al., 2018).

\section{Detection of Bio-warfare agents}

Various molecular and microbiological sensing approaches are used to track bio warfare agents. Currently, immunoassays, biochemical spectrometry, microbiological culture and genomic analysis PCR are used to identify the biological agent. Many of these detection approaches have drawbacks including isolation problems, storage, and purification of test materials, poor detection capacity to distinguish pathological and etiological differences, physiological or structural variations (Krishan et al., 2017). Commonly used techniques for the detection of bio agents are described below.

\section{Enzyme-linked immunosorbent assay (ELISA)}

Enzyme-linked immunosorbent assay (ELISA) based system is widely used for the diagnosis of microbial infection to detect and quantify substance including antibodies, antigen, proteins, and glycoprotein, and hormone. Previously in ELIZA color change is observed if the foreign antigen is present. The ELISA-based MagPix test method relies on paramagnetic microsphere technologies that can turn ELISA into a more robust and reliable device with additional multiplexing capabilities. Latest developments in LuminexxMAP technologies deliver multiple capabilities.

A charged coupling system (CCD) camera is used to detect fluorescence from each microsphere excited by light-emitting diodes, allowing the calculation median fluorescence intensity (MFI) of each sample. This utilizes a color-coded magnetic microsphere with covalent antibodies coupled with the beads as strong support of the ELISA-like immunoassay. Nowadays this technique generates a signal and color change visible by naked eyes, blue color for positive and red for negative. This method is qualitative and hence determines only the presence or absence of an analyte and not its concentration ( $\mathrm{Lv}$ et al., 2019).

Liu et al., 2020 used ELIZA based kit to diagnose SARS-CoV-2 affected patients, visualize nucleocapsid protein (rN), and spike protein (rS) for the detection of IgM and $\mathrm{IgG}$ antibody in human plasma. From January 19 to February 26 they observed a total of 214 patients and 146-150 diagnosed with $\mathrm{rN}$ and IgM and IgG based ELIZA and 165-159 diagnosed with $\mathrm{rS}$ and $\operatorname{IgM}$ and $\operatorname{IgG}$ based ELIZA.

The positive rate for $\mathrm{rN}$ and $\mathrm{rS}$ based ELISA for $\operatorname{IgM}$ and $\operatorname{IgG}$ antibody were $(80.4 \%)$ and $(82.2 \%)$. It was also discovered that $\mathrm{rS}$ based ELISA for $\operatorname{IgM}$ detection was significantly higher than rN based ELISA. During the early stage of illness 0-10, positive rates were less by ELIZA and after 10 days, the rate was increased and drop after 35 days. Have high sensitivity for serum. 


\section{Lateral flow strip test}

The lateral flow strip test also known as immune chromatographic test (ICT) was introduced at the end of the 1980s and is prominent for rapid testing. ICT detects several analytes such as antigen, antibodies and even the nucleic acid amplification test product. One or more analytes could be simultaneously tested on the same strip utilizing ICT. The specimen may consist of semen, saliva serum, plasma or whole blood. LFIA is quick and simple to conduct, but is not too flexible and often findings are misleading. However, this technique can be beneficial for immediate initial sample screening for the existence of biological agents. Several companies have built a lateral flow device for a broad range of biological agents such as Anthraces, Clostridium botulinum, etc. LFTS have recently been equipped with sensors and modern design technologies may improve the multiplex capability of LFTS (Market et al., 2013; Wu et al., 2020).

Table.1 Examples and Classification of Bio-agents use in Bioterrorism(Bioterrorism Overview, 2008; González et al., 2017)

\begin{tabular}{|c|c|c|c|}
\hline Category & Biological agent & Disease & Characteristics \\
\hline \multirow[t]{5}{*}{$\mathrm{A}$} & Francisellatularensis. & Tularemia & \multirow{5}{*}{$\begin{array}{l}\text { These are most vulnerable agents, } \\
\text { transmit easily and } \\
\text { result in high mortality. } \\
\text { These agents require well } \\
\text { maintained public health } \\
\text { preparedness. }\end{array}$} \\
\hline & Bacillus anthracis. & Anthrax & \\
\hline & Variola virus. & Smallpox & \\
\hline & Yersinia pestis & Bubonic Plague & \\
\hline & Ebola virus & $\begin{array}{l}\text { Hemorrhagic } \\
\text { Fever }\end{array}$ & \\
\hline \multirow[t]{5}{*}{ B } & Brucella species & Brucellosis & \multirow{5}{*}{$\begin{array}{l}\text { Bio agents under this category are } \\
\text { moderately vulnerable agents and } \\
\text { are moderately disseminate. }\end{array}$} \\
\hline & Burkholderia mallei & Glanders & \\
\hline & Coxiellaburnetii & Glanders & \\
\hline & Abrusprecatorius & Abrin & \\
\hline & Rickettsia prowazekii & Typhus & \\
\hline \multirow[t]{4}{*}{$\mathrm{C}$} & Hantavirus & $\begin{array}{l}\text { Hantavirus } \\
\text { Pulmonary } \\
\text { Syndrome }\end{array}$ & \multirow{4}{*}{$\begin{array}{l}\text { These agents are engineered for } \\
\text { high dissemination. } \\
\text { They result in high mortality and } \\
\text { can cause major health Impact. }\end{array}$} \\
\hline & Nairovirus & $\begin{array}{l}\text { Crimean-Congo } \\
\text { Hemorrhagic } \\
\text { Fever }\end{array}$ & \\
\hline & Bunyaviruses & $\begin{array}{l}\text { Hemorrhagic } \\
\text { Fevers }\end{array}$ & \\
\hline & Nipah virus & Nipah Infection & \\
\hline
\end{tabular}

\section{PCR Polymerase chain reaction}

The PCR technique is the most prominent and commonly used for identification of bio agents. The main advantage of this technique is its special specificity towards to the genome of the living system. The precise design of primers and probes allows precise organism identification. The exponential amplification of the genomic signature gives this technique high sensitivity. In the PCR, a small fragment of the amplified genome 
(DNA / RNA) creates millions of copies of DNA in a limited period of time. The positive and negative controls are used in the study to avoid reaction failure and to verify the study and the instrumental results. The finding is primarily focused on the existence of metabolites in the sample and on complicated matrices. Specific improvements are being developed to the standard PCR to allow simultaneous identification of multiple dangerous agents.(Green and Sambrook et al., 2019)

\section{Real-time PCR}

Real-time (RT) PCR can simultaneously detect nucleic acid in any sample. RT-PCR can be specific and non-specific. In nonspecific RT-PCR Universal DNA interacts with dye and emit fluorescence. In specific RT-PCR sequence-specific DNA samples consisting of oligonucleotides labeled with a fluorescent reporter enables identification only after hybridization of the complementary sequence sample. Wang et al (2020) used RTPCR for SARS-COV-2 patient identification. They observed a total of 375 patients from 25 Jan to 16 March 2020. They collected serum and throat samples of the affected person and observe that the combined study of RT-PCR with antibody test is more accurate and sensitive. The result of the sensitivity and specificity of combined RT-PCR and antibody is $98.6 \%$ and $98.7 \%$.

\section{Next-genome Sequencing (NGS) technology}

NGS technology is capable of revolutionizing molecular detection science. This technique allows sequencing entire genome material and to produces metagenome. This metagenome not only detects bio threat agents but may also recognize an uncertain agent in a very short time. NGS plays a crucial function in characterizing and detecting epidemic outbreaks by whole genome sequencing of isolates where certain diagnostics collapse due to unusual and novel pathogen intervention. NGS is ideal for scanning and fast identification. Broad environmental structure. This technique contributed to the discovery of several different types of nonculturable microbial and viral agents. NGS's main drawback involves high instrument expense and complicated data analysis(Kumar et al., 2019).

\section{Biochip}

Biochips are miniaturized laboratory enables the researcher to diagnose bio threat agents. The biochip is portable, automated framework for direct environmental sampling. Kubici et $a l$. , (2016) developed a lab-on-a-chip (LOC) system for molecular analysis of anthrax. It provides rapid and sensitive detection of small amount of samples. Testing can be performed within few minutes after RT-PCR amplification and without pretreatment. This micro-device uses capillary electrophoresis and single-strand polymorphism (SSCP) approaches to detect genetic mutation linked to high pathogenic and low pathogenic type of avian influenza, but may also be used to identify other pathogen. The glass SSCP-CE chip was mounted in a robust polymer case module with integrated reservoirs for easy handling. Its use in diagnosing $\mathrm{A}(\mathrm{H} 7 \mathrm{~N} 7)$ virus sample collected during the outbreak of 2007 in UK proved it is more reliable than other techniques. This micro device is prepared to perform in the laboratory as well as for outdoor analysis, developed as a lab-in-a suitcase instrument.

In conclusion the Expanding future of microbial forensic applications is motivated by the development and availability of emerging technology like Next-generation Sequencing and bioinformatics. Public safety and monitoring are potentially new fields to challenge microbial forensics. Microbial forensics could play a major role in the identification of health-related infections in 
the field of clinical and public health. The effect of rising multidrug-resistant infections reduced pharmaceutical supplies and expanded exposure to health services has the ability to establish a safety epidemic. Sequenced phylogenetic and other technologies can replace conventional epidemiology. The development of diagnoses and therapies for transboundary diseases, particularly animal and zoonotic diseases may also be assisted by microbial forensics.

Conflict of interest- the authors declare that there is no conflict of interest

\section{Source of funding- Self}

Ethical clearance- In this article no personal data was divulged. Therefore, there is no requirement of ethical clearance.

\section{References}

Bioterrorism Overview. (2008). Centers for Disease Control and Prevention. http://www.bt.cdc.gov/bioterrorism/ove rview.asp

Budowle, B., Beaudry, J. A., Barnaby, N. G., Giusti, A. M., Bannan, J. D., and Keim, P. (2007). Role of law enforcement response and microbial forensics in investigation of bioterrorism. Croatian Medical Journal, 48(4), 437-449. https://www.ncbi.nlm.nih.gov/pmc/artic les/pmid/17696298/?tool=EBI

Budowle, B., Schutzer, S. E., Burans, J. P., Beecher, D. J., Cebula, T. A., Chakraborty, R., Cobb, W. T., Fletcher, J., Hale, M. L., Harris, R. B., Heitkamp, M. A., Keller, F. P., Kuske, C., LeClerc, J. E., Marrone, B. L., McKenna, T. S., Morse, S. A., Rodriguez, L. L., Valentine, N. B., and Yadev, J. (2006). Quality sample collection, handling, and preservation for an effective microbial forensics program. In Applied and Environmental Microbiology (Vol. 72, Issue 10, pp. 6431-6438). American Society for Microbiology (ASM). https://doi.org/10.1128/AEM.01165-06

Carus, W. S. (1998). Bioterrorism and Biocrimes: The Illicit Use of Biological Agents Since 1900.

Cohen, A., Robenshtok, E., Rotman, E., and Sagi, R. (2002). The history of biological warfare. Harefuah, $141 \mathrm{Spec}$ No (Suppl 1), 7-12, 124. https://doi.org/10.1038/sj.embor.embor 849

Echeonwu, B., Nwankiti, O. O., and Chollom, S. (2018). Bioterrorism Threat: A Review of Microbial Forensics Source- Tracing of Some Bioterrorism Agents. JFSM, 4(3), 161-166. https://doi.org/10.4103/jfsm.jfsm_5_18

González, A. A., Rivera-Pérez, J. I., and Toranzos, G. A. (2017). Forensic Approaches to Detect Possible Agents of Bioterror. Microbiology Spectrum, $5(2)$, $1-12$. https://doi.org/10.1128/microbiolspec.e mf-0010-2016

Graubard, M. (1947). The Effect of Smallpox on the Destiny of the Amerindian. E. Wagner Stearn, Allen E. Stearn. Isis, $37(1 / 2)$, 124-125. https://doi.org/10.1086/348012

Green, M.R. and Sambrook, J., 2019. Polymerase chain reaction. Cold Spring Harbor Protocols, 2019(6), pp.pdbtop095109.

Hentges, D. J. (1996). Anaerobes: General Characteristics. In Medical Microbiology. University of Texas Medical Branch at Galveston. http://www.ncbi.nlm.nih.gov/pubmed/2 1413255

Krishan, K., Kaur, B., and Sharma, A. (2017). India's preparedness against bioterrorism: Biodefence strategies and policy measures. Current Science, 
113(9),

$1675-1682$. https://doi.org/10.18520/cs/v113/i09/16 75-1682

Kubicki, W., Pajak, B., Kucharczyk, K., Walczak, R. and Dziuban, J.A., 2016. Rapid detection of highly pathogenic A (H7N7) avian influenza virus genetic markers in heterogenic samples utilizing on-chip SSCP-CE method. Sensors and Actuators B: Chemical, 236, pp.926-936.

Kumar, K.R., Cowley, M.J. and Davis, R.L., 2019, October. Next-generation sequencing and emerging technologies. In Seminars in thrombosis and hemostasis (Vol. 45, No. 07, pp. 661673). Thieme Medical Publishers.

Liu, W., Liu, L., Kou, G., Zheng, Y., Ding, Y., Ni, W., Wang, Q., Tan, L., Wu, W., Tang, S. and Xiong, Z., 2020. Evaluation of nucleocapsid and spike protein-based enzyme-linked immunosorbent assays for detecting antibodies against SARS-CoV-2. Journal of clinical microbiology, 58(6).

Lv, X., Huang, Y., Liu, D., Liu, C., Shan, S., Li, G., Duan, M. and Lai, W., 2019. Multicolor and ultrasensitive enzymelinked immunosorbent assay based on the fluorescence hybrid chain reaction for simultaneous detection of pathogens. Journal of agricultural and food chemistry, 67(33), pp.9390-9398.

Majumdar, A. (2017). Weapons of Mass Destruction. In ABC Research Alert (Vol. 5, Issue 1). https://doi.org/10.18034/ABCRA.V5I1. 967

Market, F.C., 2013. Lateral flow immunoassay systems: evolution from the current state of the art to the next generation of highly sensitive, quantitative rapid assays. The Immunoassay Handbook: Theory and applications of ligand binding, ELISA and related techniques, 89 .
Means, L. (2019). IS and Bioweapons: How Can the BWC Be Used to Intercede When a Non-Signator IS Suspected of Bioweapon Creation? Journal of Biosecurity, Biosafety, and Biodefense Law, https://doi.org/10.1515/jbbbl-20190002

Mohit Bhatia, Bibhabati Mishra, Archana Thakur, Vinita Dogra, P. S. L. (2016). Concept of Forensic Microbiology and its Applications. SMU Medical, 3. Naeem, Z., Sohail, N., and Iftikhar, S. (2019). Bioterrorism, an Emerging Threat. In Trends of Environmental Forensics in Pakistan (pp. 111-124). Elsevier. https://doi.org/10.1016/b9780-12-819436-2.00007-8

Panghal, A., and Flora, S. J. S. (2019). Viral agents including threat from emerging viral infections. In Handbook on Biological Warfare Preparedness (pp. 65-81). Elsevier. https://doi.org/10.1016/B978-0-12812026-2.00004-9

Pattnaik, P., and Jana, A. M. (2005). Microbial forensics: Applications in bioterrorism. Environmental Forensics, 6(2), 197-204. https://doi.org/10.1080/1527592059095 2874

Saalbach, K. P. (2019). Biological warfare. In Encyclopedia of Microbiology (pp. 520-525). Elsevier. https://doi.org/10.1016/B978-0-12801238-3.62160-8

Sathua, K., and Flora, S. J. S. (2019). Bacterial biological warfare agents. In Handbook on Biological Warfare Preparedness (pp. 13-31). Elsevier. https://doi.org/10.1016/B978-0-12812026-2.00002-5

Tara Kartha. (2020, April 3). Is Covid-19 a Chinese weapon or an accident? Either way, world must stop playing in bio labs. The Print. 
https://theprint.in/opinion/covid-19-achinese-weapon-or-an-accident-worldmust-stop-playing-in-bio-labs/394160/

Tucker, J. B. (2001). The "yellow rain" controversy: Lessons for arms control compliance. Nonproliferation Review, $8(1), 25-42$.

https://doi.org/10.1080/1073670010843 6836

Wang, P., 2020. Combination of serological total antibody and RT-PCR test for detection of SARS-COV-2 infections. Journal of virological methods, p.113919.

Wu, Y., Zhao, Y., Leng, Y., Lai, W., Huang, $X$. and Xiong, Y., 2020. Emerging design strategies for constructing multiplex lateral flow test strip sensors. Biosensors and Bioelectronics, p.112168.

\section{How to cite this article:}

Tahir ul Gani Mir, Prama Rani and Adeebullah Nawim. 2020. Bioterrorism; Dual Use of Technology and Role of Law Enforcement to Combat Biological Attack. Int.J.Curr.Microbiol.App.Sci. 9(09): 1408-1418. doi: https://doi.org/10.20546/ijcmas.2020.909.178 